\title{
Meio ambiente, produção do espaço urbano e relações de poder: Um estudo sobre a implantação de parques em Ribeirão Preto - SP
}

\section{Felipe de Souza Ramão}

\section{OpenEdition}

\section{Journals}

Edição electrónica

URL: http://journals.openedition.org/espacoeconomia/1653

DOI: 10.4000/espacoeconomia.1653

ISSN: 2317-7837

Editora

Núcleo de Pesquisa Espaço \& Economia

Refêrencia eletrónica

Felipe de Souza Ramão, « Meio ambiente, produção do espaço urbano e relações de poder: Um estudo sobre a implantação de parques em Ribeirão Preto - SP », Espaço e Economia [Online], 6 | 2015, posto online no dia 08 agosto 2015, consultado o 01 maio 2019. URL : http:// journals.openedition.org/espacoeconomia/1653 ; DOI : 10.4000/espacoeconomia.1653

Este documento foi criado de forma automática no dia 1 Maio 2019.

(c) NUPEE 


\section{Meio ambiente, produção do espaço urbano e relações de poder: Um estudo sobre a implantação de parques em Ribeirão Preto - SP}

Felipe de Souza Ramão

REFERÊNCIA

GOMES, Marcos Antônio Silvestre. Os Parques e a Produção do Espaço Urbano. Jundiaí, SP: Paco Editorial, 2013. 


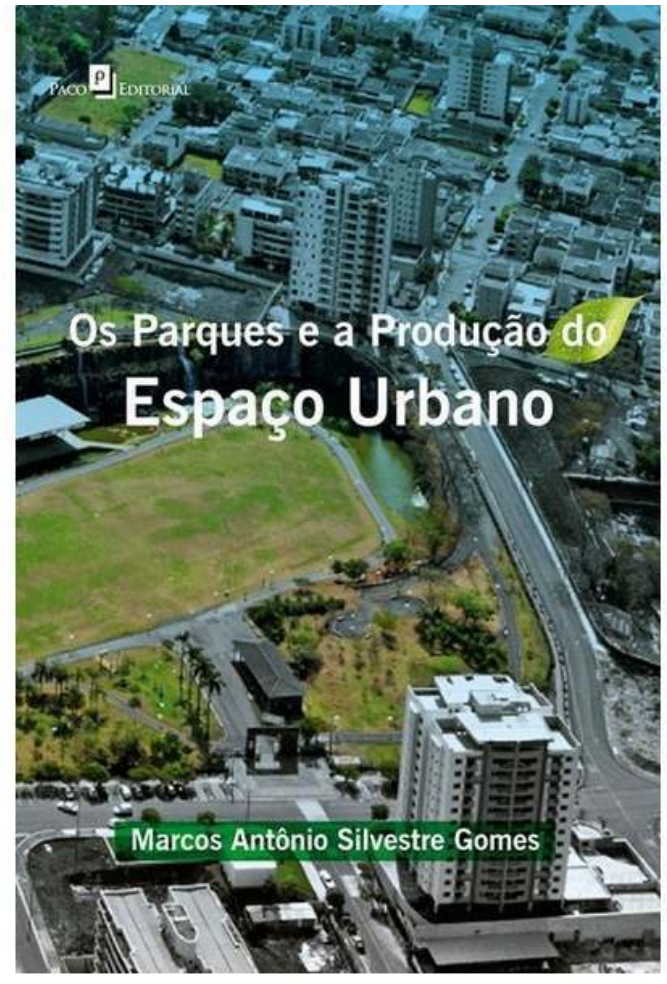

1 Em um cenário atual, onde a discussão ambiental ainda é feita em parte por meio de análises superficiais e romantizadas ${ }^{1}$, o livro "Os Parques e a Produção do Espaço Urbano", de Marcos Antônio Silvestre Gomes, surge como uma proposta de reflexão crítica, questionando o discurso verde - amplificado nas últimas décadas - em conjunto com o processo de mercantilização da natureza. Além da discussão teórica, o livro apresenta um estudo de caso sobre a questão dos parques na produção do espaço da cidade de Ribeirão Preto, em São Paulo, mostrando as relações de poder intrínsecas no discurso ambiental. A cidade de Ribeirão Preto é analisada a partir de um processo histórico-geográfico, de constantes e intensas mudanças e ritmos na economia, na população e nas políticas públicas.

2 Se a partir do título e da capa do livro, o verde aparenta ser o nexo estruturante para compreender a produção do espaço, e, de fato possa parecer mais uma discussão romantizada ou de como os parques são importantes para a cidade (para a qualidade de vida da população, entre outros jargões ecológicos), desde a contracapa, o autor mostra que os fatores políticos, alinhados com os interesses econômicos, são preponderantes para a compreensão do processo de produção do espaço na cidade do interior paulista. Em nossa opinião, seria de grande importância indicar no título ou em um subtítulo a relevância geopolítica do trabalho ou das relações de poder no espaço, mesmo compreendendo que a produção do espaço é política, assim como uma referência para a cidade de Ribeirão Preto, já que a cidade é escolhida como objeto empírico.

3 O discurso verde, travestido nos ideais de conservação e de qualidade de vida, é uma forma de expandir e alimentar interesses do poder público e de agentes privados, e, consolidou-se como uma mercadoria importante, com grande potencial de valorização do espaço, assumindo forma principalmente nas políticas públicas, e, o livro será cirúrgico ao mostrar as funções do poder público nesse contexto. 
O autor oferece uma grande colaboração para a Geografia, por mostrar como a natureza é importante na produção e na valorização do espaço (mostrando o espaço além da concepção de palco para a ação do homem), e, como a produção da natureza ou a natureza artificializada está ligada a estratégias de poder, ainda que, contudo, no discurso oficial, proclame-se a importância da conservação e do termo em voga desde a década de 1980, do desenvolvimento sustentável. Será visível o quanto esses discursos são estrategicamente vagos e superficiais, assim como, a inserção da lógica verde nas políticas públicas nem sempre estarão preocupadas em conservar áreas de grande interesse ambiental; destarte, o autor dialoga com vários campos das ciências sociais, consequentemente, mostrando que o debate não está restrito a ciência geográfica e que a leitura do livro é pertinente para várias áreas que tratam do tema meio ambiente ou natureza.

Inicialmente, o autor apresenta e analisa a cidade de Ribeirão Preto, reconhecida no século XX como a "Califórnia Brasileira", ressalta o processo de produção do espaço urbano, a base econômica em diferentes momentos históricos, e, como a cidade está inserida na lógica do estado, do país e do mundo, principalmente a partir da economia agrícola no começo do século $\mathrm{XX}$, e, do processo de modernização - reflexo do período técnico-científico-informacional - das últimas décadas do mesmo século.

6 As dinâmicas urbana, rural e demográfica serão alteradas a partir das transformações econômicas, produtivas e tecnológicas, que terão o incentivo e muitos investimentos públicos, desde a esfera municipal até a esfera federal, e, da iniciativa privada. As atividades agrícolas assim como o espaço rural continuam sendo uma importante referência para a cidade, mas o espaço urbano se expande de forma substantiva, revelando-se como outra importante fonte de lucro.

7 Complementarmente, o autor trava a sempre difícil discussão da relação entre meio ambiente e espaço urbano, que aparece de forma geral como uma relação inconcebível, devido ao imaginário do meio ambiente como um espaço não construído ou que aparece na frágil discussão de manchas do espaço natural na cidade, sem considerar fatores econômicos e políticos. Desde a década de 1970, com a ampliação da discussão ambiental a nível mundial, através de conferências, correntes ambientalistas, políticas, leis, etc., o verde passou a ser cada vez mais importante e introduzido no espaço urbano, no Brasil tendo um grande impulso com a Segunda Conferência das Nações Unidas sobre Meio Ambiente e Desenvolvimento - ECO 92, no Rio de Janeiro.

8 As políticas ambientais, já incorporadas no bojo das preocupações do capital, são estratégias para a expansão do capitalismo na segunda metade do século XX, já que são produzidas por grandes instituições, organizações, empresas e países que simbolizam os interesses das classes dominantes. Logo, o uso de verde no espaço urbano também se torna uma importante estratégia do capital, que são visíveis nos parques, nas praças, áreas arborizadas, no lazer, nos condomínios murados, nos bairros jardins, a partir de símbolos, ícones, status e falsas necessidades, que assumem grande valor comercial (GOMES, 2013).

9 O autor usa de mapas para localizar a cidade no estado de São Paulo, para identificar os setores urbanos, os parques urbanos e para compreender a relação da expansão urbana com os fragmentos da vegetação natural; utiliza de diversos dados para mostrar o desenvolvimento da economia, da dinâmica demográfica e de fatores sociais, sendo relevantes, mesmo nem sempre demonstrando com fidelidade a realidade; e as 
consequências sociais do processo de produção desigual do espaço e de uma economia atrativa em uma escala regional, como a favelização, a miséria e a insuficiência de serviços públicos.

10 De todas as análises de mapas e dados, faz-se mister destacar o mapa de identificação dos parques urbanos, que demonstra a desigual localização geográfica dos parques, segundo o autor: "os parques não se encontram bem distribuídos ao longo da malha urbana, de forma que favoreça seu uso por todas as parcelas da populaçãa" (GOMES, 2013, p. 58), o que provoca a tensão do "meio ambiente enquanto um bem coletivo" versus "meio ambiente como mercadoria", apropriada pela classe dominante. Esse debate é extremamente frutífero, pois no plano do discurso o meio ambiente continua sendo coletivo, principalmente sendo proferido pelo poder público (nos discursos dos prefeitos, por exemplo, como mostrado no decorrer do livro) e registrado em documentos oficiais, como o plano diretor (também analisado), porém o que o autor nos mostra é que na realidade de Ribeirão Preto, a construção de parques, assim como de outras áreas verdes, obedece a uma localização e um objetivo específico - valorizar áreas ricas e de interesse imobiliário, mostrando a sintonia entre os gestores públicos e os agentes privados, e, a grande relevância do espaço.

11 O discurso ambiental é trabalhado não só como a presença de "verde" no espaço urbano, mas do significado simbólico que o "verde" tem no espaço urbano, como um espaço de tranquilidade, como referência de qualidade de vida, de recreação e de lazer, com grande valor estético, o que também são fatores incorporados como estratégia de vários agentes no processo de produção do espaço urbano, como os agentes imobiliários (GOMES, 2013, p. 60).

12 O autor se utiliza de importantes referências para analisar a questão do verde enquanto lazer, dessa forma: esse papel de relevância do verde surge a partir de um contexto urbano de barulho, de fadiga, de poluição, e, na busca de uma "natureza pura", quase sempre no campo, para ser vendida e funcionar como valor de troca (LEFEBVRE, 2006), e, assim, a busca do campo não se confunde com a busca pelo modo de vida do campo, e, as casas do campo não podem ser casebres, mas mansões para atender à aristocracia (WILLIAMS, 1989; THOMAZ, 1988).

13 Desde o século XIX, nos Estados Unidos, há uma política ambiental com linhas conservacionistas, responsável pela criação de parques, tendo como auge o Parque de Yellowstone, em 1872, que foi o primeiro parque de conservação do mundo. 0 parque de Yellowstone significava no seu discurso a preocupação com a vida dos animais, com a conservação do verde, com a qualidade de vida e com o lazer da população, combatendo o processo de degradação ambiental já visualizado em grande escala no país, mas é preciso se atentar para o conturbado processo de construção do parque norte-americano, com um processo de remoção de tribos indígenas e com a posterior entrega da gestão desse parque e futuramente de outros parques para sociedades privadas (DIEGUES, 2004).

Portanto, Marcos Gomes mostra que é de fundamental importância compreender a gênese da construção de parques a nível mundial e posteriormente a nível nacional, assim como toda a evolução e o desdobramento das políticas ambientais na segunda metade do século XX, para analisar o processo na cidade de Ribeirão Preto. O trabalho com diversas escalas será fundamental: [I] para o efeito de comparação entre processos de escalas diferentes, por exemplo, a farsa e o caráter estratégico de Yellowstone serão semelhantes ao visto no processo de construção de parques em Ribeirão Preto; e [II] para compreender processos 
que escapam da escala do local, como a ação dos agentes produtores do espaço, que em muitos momentos se dá a partir de relações entre várias escalas.

No âmbito das cidades brasileiras, o discurso da cidade-verde surgiu como uma grande marca do desenvolvimento sustentável, alinhado com os ideais já mencionados, como qualidade de vida e lazer, entre outros. Um dos grandes símbolos de cidade ecologicamente correta e referência em espaços verdes no Brasil, com repercussão internacional, é a cidade de Curitiba (PR), capital ecológica, tendo entre 1972 e 2003 a criação de 30 parques e 300 praças, além de vários bosques (GOMES, 2013, p. 79). Contudo, como visto em Sanchéz e Moura (1999), a ideia de cidade-modelo, proferida e reproduzida a nível internacional enfrenta barreiras e incongruências, principalmente no que se refere à fragmentação e à segmentação do território que revela as desigualdades socioeconômicas existentes.

O exemplo de Curitiba é importante para identificar que na cidade brasileira com a maior imagem de sustentabilidade se faz notória a disparidade socioespacial, e, que nesse sentido, o meio ambiente não é para todos. $\mathrm{E}$, de forma semelhante, esse processo acontece na cidade de Ribeirão Preto, contudo com algumas especificidades que a cidade do interior de São Paulo nos oferece.

17 O grande objetivo do autor nesse momento foi mostrar que a construção de parques em Ribeirão Preto significou parte de uma estratégia de valorização fundiária para a apropriação do capital, a partir de uma inescrupulosa parceria entre o público e o privado. $O$ autor menciona outras áreas verdes da cidade, principalmente, as que teriam uma relevância ecológica maior e não são valorizadas. Entretanto, ele concentra seus esforços nos dois principais parques da cidade: o Parque Prefeito Luiz Roberto Jábali, fruto de uma desapropriação, e o Parque Dr. Luís Carlos Raya, parte de uso comum do loteamento Jardim Botânico.

18 Em ambos os casos, o autor afirma que o processo de construção dos parques - cujas inaugurações foram em 2002 e 2004, respectivamente - foi importante para a valorização dos espaços ao entorno, que já eram consolidados como espaços de grupos de elite, ou seja, há uma nova valorização de áreas já aquilatadas. Logo, o autor apresenta a evolução do preço do solo, com três períodos marcantes: em 1995, em 1998 [antes da inauguração dos parques] e em 2007/2008 [depois da inauguração dos parques], a partir de uma tabela, comparando áreas mais ricas e mais pobres da cidade, e, os possíveis efeitos do funcionamento dos parques, com o aumento significativo do preço do solo nas áreas do entorno do parque.

19 “Transformadas em parques, estas áreas tornam-se novas raridades no espaço urbano. Como terras públicas, não entram no mercado de compra e venda, mas alteram o preço das terras nas imediações" (GOMES, 2013, p. 98). Dessa forma, faz-se necessário advertir que não é apenas uma área verde capaz de possuir esse simbolismo e esse valor comercial, mas um espaço verde organizado, oficial, estruturado, com segurança e que carregue todo o discurso ambiental já mencionado, e, assim, pode ser uma excelente mercadoria para as empresas e para o poder público, valorizando o preço da terra e dos imóveis.

20 A análise dos parques em Ribeirão Preto significa a reflexão da problemática que envolve o planejamento e a gestão dos espaços públicos e a interferência desses espaços na dinâmica da produção do espaço urbano, concomitantemente, como as empresas se apropriam do discurso verde e se utilizam das parceiras com o poder público para ampliar o seu domínio e o seu lucro. Nesses parques, o verde perde o significado ou o valor 
ambiental para ganhar valor de troca, valor simbólico, estético, fundiário, que ao invés de servir a toda a população, serve aos interesses das classes dominantes.

Por fim, ressalta-se o brilhante raciocínio de Mauricio Waldman (1998, p. 12), utilizado por Gomes, que de certa forma expressa e sintetiza o esforço hercúleo de produzir uma análise crítica do meio ambiente: "a discussão ecológica não mais pode se restringir a uma luta 'poética' ou simplesmente preservacionista, mas deve ser encarada como uma luta política, econômica, social e ideológica".

\section{BIBLIOGRAFIA}

DIEGUES, A. C. 0 mito moderno da natureza intocada. $4^{\mathrm{a}}$ edição. São Paulo: HUCITEC/Nupaub - USP, 2004.

LEFEBVRE, H. O direito à cidade. $4^{a}$ edição. São Paulo: Centauro, 2006.

LEFEBVRE, H. A revolução urbana. Belo Horizonte, MG: Ed. UFMG, 1999.

SÁNCHEZ, F.; MOURA, R. Cidades-modelo: espelhos de virtude ou reprodução do mesmo? Cadernos IPPUR, Rio de Janeiro: UFRJ, IPPUR, Ano XIII, nº.2, p. 95-114, 1999.

THOMAS, K. O homem e o mundo natural: mudanças de atitudes em relação às plantas e aos animais (1500 - 1800). São Paulo: Companhia das Letras, 1988.

WALDMAN, Mauricio. Ecologia e lutas sociais no Brasil. 4ª edição. São Paulo: Contexto, 1998.

WILLIAMS, R. O campo e a cidade na história e na literatura. São Paulo: Companhia das Letras, 1989.

\section{NOTAS}

1. Na Geografia ainda há uma questão relevante, que é o tratamento do meio ambiente a partir da Geografia Física, que muitas vezes privilegia elementos físicos, como o relevo, o solo, a vegetação, com a superficial abordagem de "homem destruidor do meio ambiente" ou dos "efeitos dos impactos ambientais na vida do homem", sem considerar fatores políticos, econômicos e ideológicos. 


\section{AUTOR}

\section{FELIPE DE SOUZA RAMÃO}

Mestre em Geografia pela UERJ, com especialização em Educação Ambiental - IFF/Cabo Frio e graduado no curso de Licenciatura em Geografia - Ferlagos (Faculdade da Região dos Lagos), Cabo Frio - RJ. Integrante do Núcleo de Pesquisa Espaço e Economia (NuPEE). Professor da SEEDUC - RJ. 